\title{
Chronic non-cancer pain in primary care: an Italian cross-sectional study
}

\author{
Arianna Camilloni ${ }^{1}$, Giulio Nati ${ }^{1}$, Paolo Maggiolini ${ }^{2}$, Antonio Romanelli ${ }^{2, *}$, \\ Gianni Carbone ${ }^{2}$, Diana Giannarelli ${ }^{3}$, Irene Terrenato ${ }^{3}$, Maria Grazia De Marinis ${ }^{4}$, \\ Adriano Rossi ${ }^{5}$, Daniela D'Angelo ${ }^{6}$, Rosaria Ferrara ${ }^{7}$, Laura Iacorossi ${ }^{8}$, \\ Antonella Paladini ${ }^{9}$, Giustino Varrassi ${ }^{10}$, Gianfranco Tarsitani ${ }^{1, \dagger}$, Roberto Latina ${ }^{2, \dagger, *}$
}

\author{
${ }^{1}$ Sapienza University, Rome, Italy \\ ${ }^{2}$ School of Nursing \& Midwifery, \\ Sapienza University, AO San \\ Camillo-Forlanini Hospital, C.ne \\ Gianicolense n.87, 00152 Rome, Italy \\ ${ }^{3}$ Biostatistic and Bioinformatic Unit, \\ IRCCS Regina Elena National Cancer \\ Institute, Rome, Italy \\ ${ }^{4}$ Nursing Research Unit Campus \\ Bio-Medico University, Rome, Italy \\ ${ }^{5}$ School of Medicine and Surgery, \\ University of Milano-Bicocca,Milan, Italy \\ ${ }^{6}$ Tor Vergata University, Rome, Italy \\ ${ }^{7}$ Department of Psychiatry CHUV, \\ Faculty of Biology and \\ Medicine,Lousanne, Switzerland \\ ${ }^{8}$ School of Nursing, Sapienza University, \\ IRCCS Regina Elena National Cancer \\ Institute, Rome, Italy \\ ${ }^{9}$ MESVA Università dell'Aquila,Italy \\ ${ }^{10}$ Paolo Procacci Foundation, Roma, \\ Italy

\section{*Correspondence \\ antonioromanelli10@gmail.com \\ (Antonio Romanelli) \\ roberto.latina@uniroma1.it \\ (Roberto Latina) \\ $\dagger$ These authors contributed equally.}

\begin{abstract}
Chronic non-cancer pain is a complex health condition that affects more than a quarter of the Italian population who mainly refers to general practitioners and primary care for their treatment. There are little information on the epidemiological and clinical characteristics and types of treatments for these patients who suffer from chronic pain. The aim of the study was to provide epidemiological and clinical information about patients with chronic non-cancer pain who refers to GPs for their treatment. An observational, multicentre, cross-sectional study was carried out using retrospectively reviewed clinical records from 29 GPs. Some pharmacoeconomic aspects were also investigated. A total of 1,007 patients who had chronic pain were selected for the study. Chronic pain was more common in women than in men (ratio $2.7: 1)(P=0.002)$. With regard to incomes, the women earned less than the men $(P=0.017)$. The chronic pain was musculoskeletal $(73.4 \%)$, mixed $(21.4 \%)$, neuropathic $(4.9 \%)$ and visceral $(0.3 \%)$. More women than men had pain in two or more sites, and $33.5 \%$ of the patients reported more than one diagnosis that related to chronic pain. The general practitioners had prescribed nonsteroidal anti-inflammatory drugs for $71.8 \%$ of the cases, opioids for $16.9 \%$, adjuvants for $9.0 \%$ and acetaminophen for $2.4 \%$, and about pharmacoeconomic aspects, the total cost for the sample was $€ 111,331.42$. Primary care is the essential frontline for patients who suffer from non-cancer pain. An interdisciplinary assessment and approach should start in primary care delivery to maximize the clinical outcomes.
\end{abstract}

\section{Keywords}

Primary care; Epidemiology; General Practitioner; Chronic Pain; Pain Management; Italy; General Population

\section{Introduction}

Chronic non-cancer pain (CP) is generally recognized as a major public health problem and is one of the most common reasons why patients seek medical care [1]. Chronic pain can have devastating impact on well-being, daily activities [2-4], with clinical, social and economic burdens $[5,6]$. Indeed, the costs of chronic pain are expected to increase to an estimated $\$ 10.29$ billion per year by 2025 [7], without do not include societal costs [8]. Chronic pain should be looked at as a chronic condition in itself; a disease in its own right [9]. A recent review of studies reported that the prevalence of chronic pain in the general adult populations worldwide ranged from $8 \%$ to $30 \%$ [10], and in Italy, chronic pain affects about $28 \%$ of the population [11].

Primary care physicians are at the forefront of chronic pain management. The prevalence of chronic pain in primary care increases with age $[12,13]$ and is found more often in patients who are older than 60 years [14]. According to previous studies, the prevalence of chronic pain in elderly populations varies considerably, ranging from $27 \%$ to $86 \%$ [15]. Chronic pain is prevalent among widows, people who are divorced and those who are unemployed but appears to be inversely related to education [16]. This type of pain is more common among women than men [11, 12,17], with women experiencing pain in more sites and with greater intensities [18, 19], and is mainly musculoskeletal rather than of a neuropathic or mixed nature [19]. Chronic pain has an average duration of 7.6 years [16] and mainly involves the back and lower back, neck, limbs, and joints [20]. Patients who have chronic pain also visit their GPs twice as often as patients who do not [21]. Consultations on pain account for $22 \%$ of all primary care consultations [22]. GPs should perform initial holistic assessments that include the severity, impacts and types of pain that patients are experiencing [23]. In addition, programs are likely to be optimized when implemented in the context of continuity of 


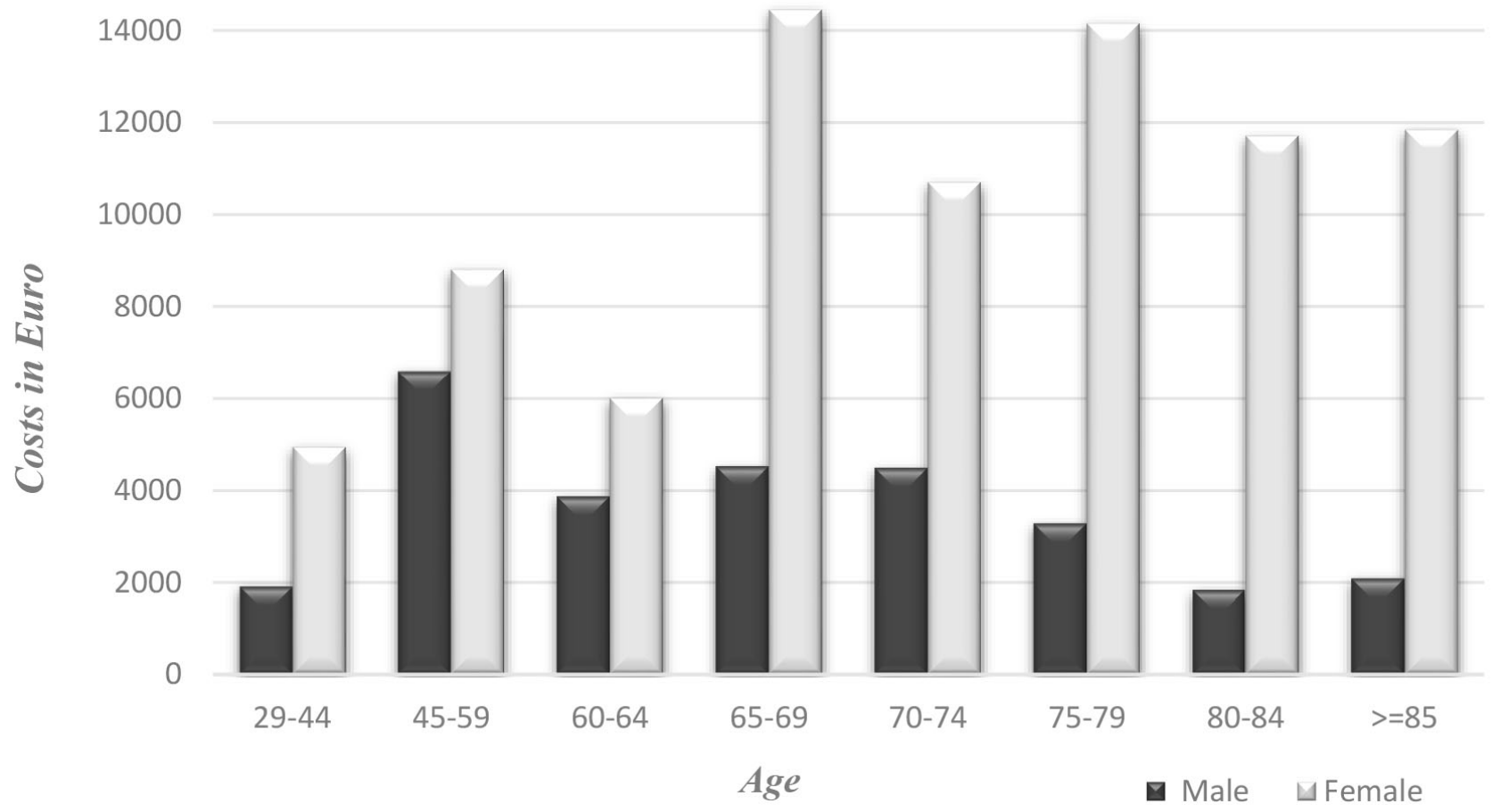

F I G U R E 1. Costs of treatments between age and sex.

care $[24,25]$.

GPs could offer treatments and better approaches for patients with chronic pain, using pharmacological and non-pharmacological interventions implemented through a network of services [26, 27]. Initial treatment is recommended with non steroidal anti-inflammatory drugs (NSAID), adjuvants and opioids. However, the high prevalence of comorbidity in patients with chronic pain may limit the applicability and usefulness of clinical guidelines [28], and for this reason GPs and nurses can support non-pharmacological treatments as complementary or integrative therapies that are commonly used along with pain control regimens [29]. Whatever interventions are prescribed, it is important for GPs to evaluate and re-evaluate these at all phases of the chronic pain management [30]. An overall reduction in the intensity of pain, by $30 \%$ to $50 \%$, is formally considered to be a successful outcome, as is an overall improvement in quality of life [31]. The successful management of chronic pain in primary care relies on multidisciplinary and holistic approaches aimed at both minimizing pain as much as possible and teaching patients how to live well with chronic pain [32]. In Italy, management for chronic pain is described in hospitals $[22,33,34]$ and pain clinics $[4,19,35]$; however, this does not necessarily reflect what happens among patients who rely on their GPs to treat their pain. It can be said, then, that the epidemiology and treatment of chronic pain in the general population is almost unknown [26].

Therefore, the goal of this study is to describe the management of chronic pain among primary care settings in Italy.

\section{Material and methods}

\subsection{Study design}

A retrospective chart review was conducted. Patients who attended primary care centres in the Latium region at least once in 2011 (either as a first visit or subsequent visits) were the target population. The data were collected between December 2012 and January 2014. This research report was written according to the Strengthening the Reporting of Observational Studies in Epidemiology Recommendations [36].

\subsection{Sample}

The study included records of patients, who were selected from the 29GPs belonging to the Italian Society of General Medicine (SIMMG), which is connected to the project management of data. A consecutive series of patients satisfying inclusion criteria with variable sampling fractions from each of the 29 GPs yielded a sample of clinical records that the GPs had completed. Information was extracted using a structured template to standardize the clinical information that the GPs had collected and used.

\subsection{Definition of "chronic non-cancer pain case"}

Although chronic non-cancer pain as been defined as pain that persists or recurs for more than three months [9], we used the standard definition of the International Association for the Study of Pain (IASP) that defines chronic pain as an unpleasant 
sensory and emotional experience with a duration of over six months [37]. However, in the 2014 International Classification of Diseases (ICD), chronic pain diagnoses were not published.

\subsection{Inclusion and exclusion criteria}

The inclusion criteria were male and female adults aged over 18 years who had attended primary care in the Latium region from January 1, 2011, to December 31, 2011, and whose medical records reported either diagnoses of chronic pain or that they had consumed a number of packs of analgesics in the fourth quartile of consumption of painkillers (over three packs). Patients who had accessed primary care during the study period and had not yet received diagnoses of chronic pain but were suffering pain were also included. Only patients with pain that was not caused by cancer were included. Patients with migraines, headaches and pain resulting from cancer were excluded. Patients with incomplete or unclear medical records were also excluded.

\subsection{Data collection}

Data from the primary care centres were collected by two members of the research team (A.C. and A.R.). When demographic variables were available, they were extracted from the records using the database software for Windows (Win-world). The following variables were collected: patient identification codes; demographic variables including age and sex; clinical variables such as the ICD-9 codes; the nature of the pain (musculoskeletal, neuropathic, mixed and visceral) [9]; the sites and numbers of the locations of pain; the allopathic treatment including NSAIDs, opioids, adjuvants and acetaminophen; about pharmacoeconomic aspects, the average costs of the treatments and the incomes are described.

\subsection{Statistical analysis}

The mean with its relative standard deviation (SD) and median values for were used for summarized quantitative variables, while absolute and relative frequencies were used for qualitative variables. Associations between qualitative variables were assessed through Pearson's Chi-square tests. Univariate and multivariate analyses were carried out to investigate which variables were associated with chronic pain, considering the different nature of the pain (neuropathic and mixed pain $v s$ musculoskeletal) as the dependent variable. Odds ratios (OR) and their relative 95\% Confidence intervals (95\% CI) were calculated for all the demographic and clinical characteristics of the patients. Statistical significance was set at a value of $P$ $<0.05$, using SPSS Version 22.0 (IBM Corp., Armonk, NY, USA) software.

\subsection{Ethics committee}

The study was reviewed and approved by the research group's internal review board, which was the relevant cross-institutional committee responsible for assessing the methodological appropriateness and ethicality of the study design. The study was approved by the Ethical Committee (prot. 456/12). Data of treatment observed fundamental rights and liberties (article 13 Italian Law 196/2003; guidelines for data processing Ministerial Decree July 5, 1997, and Law Decree 200/2007) and the Helsinki Declaration (Ethical Guidelines for Observational Studies). The research involved anonymised records and data sets that exist in the public domain, where appropriate permissions have already been obtained, and it is not possible to identify individuals from the information provided.

\section{Results}

\subsection{Age distribution and income}

The study examined 1,007 patients affected by chronic noncancer pain. Of these patients, 73.0\% (735) were women, and $27.0 \%$ (272) were men. The sample had a mean age of 69.2 years ( $\mathrm{SD} \pm 13.9$ ), from 27 to 97 years; $51.5 \%$ (519) of the sample was 70 years of age or over, and only $4.0 \%$ of the patients were less than 40 years old. Almost $50 \%$ of the sample had suffered from chronic pain for over four years (Table 1). Chronic pain was more common among women than men (ratio $2.7: 1$ ), and the difference was statistically significant $(P=0.002)$. With regard to incomes, $16.9 \%(170)$ of the patients earned $€ 36,151.98$ a year or less. The results indicate that the women earned less than the men $\left(\chi^{2}=35.730\right.$, $\mathrm{df}=20 ; P=0.017)$.

\subsection{Sites of pain}

The results showed that the women experienced pain in more sites than the men: $34.6 \%$ of the women complained of chronic pain in two or more sites, whereas in men this was $30.5 \%\left(\chi^{2}\right.$ $=6.759$, df $=2 ; P=0.034)$. The number of sites increased with age, but this was not statistically significant $\left(\chi^{2}=8.212\right.$, $\mathrm{df}=12 ; P=0.768$, data not shown). Table 2 describes the differences between the sexes in terms of the locations of the body $\left(\chi^{2}=304.0, \mathrm{df}=288 ; P=0.248\right)$.

\subsection{Nature, classification, and clinical diagnosis of pain}

The chronic pain was mostly musculoskeletal $(73.4 \%)$, followed by mixed $(21.4 \%)$, neuropathic $(4.9 \%)$ and visceral $(0.3 \%)$. The nature of the pain was not statistically significantly different between men and women $\left(\chi^{2}=9.825\right.$, df $=5 ; P=0.081)$, as shown in Table 1 , or between the age groups (data not shown). Table 3 reports the clinical diagnoses described in the medical databases of each GP according to the ICD-9. For the majority of patients, chronic pain was caused by musculoskeletal conditions such as osteoarthritis, sciatica, low back pain and displacement of intervertebral discs. Neuropathic pain was reported mainly in cases of herpes zoster, polyneuropathy and trigeminal neuralgia, and visceral pain was very seldom reported. More than half of the patients $(66.5 \%)$ reported chronic pain as a result of a single diagnosis based on the ICD-9 code.

\subsection{Risk factors for chronic pain}

Table 4 describes the results of the univariate and multivariate logistic regression model. Chronic neuropathic pain was more common in patients who were over 70 years of age $(P=0.004)$, 
TAB L E 1. Distribution of age and sex.

\begin{tabular}{|c|c|c|c|c|c|c|c|}
\hline \multirow[t]{2}{*}{ Variables } & \multicolumn{2}{|c|}{ Male $(N=272)$} & \multicolumn{2}{|c|}{ Female $(N=735)$} & \multicolumn{2}{|c|}{ Total $(N=1,007)$} & \multirow[t]{2}{*}{$P$-value } \\
\hline & $\mathbf{n}$ & $\%$ & $\mathbf{n}$ & $\%$ & $\mathbf{n}$ & $\%$ & \\
\hline \multicolumn{8}{|l|}{ Age } \\
\hline$<40$ & 12 & 4.4 & 28 & 3.8 & 40 & 4.0 & 0.002 \\
\hline $40-49$ & 23 & 8.5 & 56 & 7.6 & 79 & 7.8 & \\
\hline $50-54$ & 17 & 6.3 & 24 & 3.3 & 41 & 4.1 & \\
\hline $55-59$ & 15 & 5.5 & 53 & 7.2 & 68 & 6.8 & \\
\hline $60-64$ & 41 & 15.1 & 84 & 11.4 & 125 & 12.4 & \\
\hline $65-69$ & 50 & 18.4 & 85 & 11.6 & 135 & 13.4 & \\
\hline$\geq 70$ & 114 & 41.9 & 405 & 55.1 & 519 & 51.5 & \\
\hline \multicolumn{8}{|l|}{ NumberSites } \\
\hline 1 & 166 & 51.8 & 417 & 67.6 & 583 & 69.3 & 0.034 \\
\hline 2 & 55 & 24.6 & 170 & 27.6 & 225 & 26.8 & \\
\hline 3 & 3 & 1.3 & 30 & 4.9 & 33 & 3.9 & \\
\hline \multicolumn{8}{|l|}{ Duration } \\
\hline$<48$ months & 149 & 54.8 & 369 & 50.2 & 518 & 51.4 & 0.322 \\
\hline $48+$ months & 123 & 45.2 & 366 & 49.8 & 489 & 48.6 & \\
\hline \multicolumn{8}{|c|}{ Nature of Chronic Pain } \\
\hline Muscoloskeletal & 191 & 70.2 & 548 & 74.6 & 739 & 73.4 & 0.081 \\
\hline Visceral & 0 & 0 & 3 & 0.4 & 3 & 0.3 & \\
\hline Neuropathic & 18 & 6.6 & 31 & 4.2 & 49 & 4.9 & \\
\hline Mixed & 63 & 23.2 & 153 & 20.8 & 216 & 21.4 & \\
\hline
\end{tabular}

along with greater numbers of sites on the locations in their bodies $(P<0.001)$, and was treated with NSAIDs and opioids $(P<0.001)$ and also, in particular, with adjuvants $P<0.001)$.

\subsection{Analgesic treatments}

The study examined 2,213 prescriptions for 52 molecule treatments (data not shown). The different treatments used by the patients for chronic pain include NSAIDs, opioids (weak and strong), adjuvants and acetaminophen. There is an increasing trend to prescribe adjuvant medications for female patients to improve pain management $\left(\chi^{2}=9.33\right.$, df $\left.=1 ; P=0.005\right)$, and this is shown in Table 1. The GPs had prescribed the following: NSAIDs for $71.8 \%(1,589)$, opioids for $16.9 \%$ (373), adjuvants for $9.0 \%$ (199) and acetaminophen for $2.4 \%$ (52). The distribution of pharmacological classes indicates differences between the sexes: male use was $70.1 \%$ NSAIDs (399), while use of these among woman was $72.3 \%(1,190)$. Opioids use was $15.1 \%$ in men (86) and $17.5 \%$ in women (287). Adjuvant use by men was $12.3 \%$ (70) and $7.9 \%$ in women (129). The use of acetaminophen in men was $2.5 \%$ (14) and $2.3 \%$ (38) in women. In general, women used more pharmacological treatments than men $(\mathrm{p}<0.001)$. Moreover, the use of weak and strong opioids was $29.8 \%$ (300). Of these $69 \%$ (207) for musculoskeletal chronic pain, and 31\% (93) for neuropathic chronic pain.

\subsection{Pharmacoeconomic aspects}

The total cost for 1,007 patients suffering from chronic noncancer pain was $€ 111,331.42$, while the cost for each patient was $€ 110.56$. The highest expenditure was recorded in the 65 to 69 -year-old age group (Figure 1). In patients aged from 60 to 64 years, the highest expenditures were most frequently recorded for men rather than women. After these ages, the costs for women were higher than for men, and the difference is statistically significant $\left(\chi^{2}=35.13 ; \mathrm{df}=1 ; P \leq 0.001\right)$.

\section{Discussion}

To the best of our knowledge, this study was the first in Italy to investigate the clinical characteristics of patients who went to GPs for the management of chronic non-cancer pain. This retrospective study sheds light on the management of chronic pain after the enactment of the Italian Law 38/2010 and the creation of the Network for the Diagnosis and Treatment of Non-cancer Chronic Pain between primary care and pain clinics. Primary care physicians are at the forefront of chronic pain management. This study shows that general populations seek consultations with their GPs for the management of chronic pain. Patients who have such pain visit their GPs twice as often as patients who do not [21], and patients were referred to pain clinics by their GP are about $40 \%$ [19]. In accordance with other studies, ours found that women are more likely than men to use primary care for the treatment of chronic pain, to use pharmacological treatments for pain, and to experience 
TA B L E 2. Body locations of pain according to sex body.

\begin{tabular}{|c|c|c|c|c|c|c|}
\hline \multirow[t]{2}{*}{ Body Locations } & \multicolumn{2}{|c|}{ Male $(\mathrm{N}=\mathbf{2 8 5})$} & \multicolumn{2}{|c|}{ Female $(\mathrm{N}=\mathbf{8 5 1})$} & \multicolumn{2}{|c|}{ Total $(N=1,136)$} \\
\hline & $\mathbf{n}$ & $\%$ & $\mathbf{n}$ & $\%$ & $\mathbf{n}$ & $\%$ \\
\hline Lumbo-sacral & 49 & 17.2 & 128 & 15.0 & 177 & 15.6 \\
\hline Lumbar, unspecified & 52 & 18.2 & 114 & 13.4 & 166 & 14.6 \\
\hline Widespreadpain & 29 & 10.2 & 116 & 13.6 & 145 & 12.8 \\
\hline Knee & 23 & 8.1 & 107 & 12.6 & 130 & 11.4 \\
\hline Upper back & 17 & 6.0 & 71 & 8.3 & 88 & 7.7 \\
\hline Neck & 28 & 9.8 & 60 & 7.1 & 88 & 7.7 \\
\hline Shoulder & 17 & 6.0 & 62 & 7.3 & 79 & 7.0 \\
\hline Legs & 15 & 5.3 & 56 & 6.6 & 71 & 6.3 \\
\hline Hip & 19 & 6.7 & 41 & 4.8 & 60 & 5.3 \\
\hline Feet & 10 & 3.5 & 23 & 2.7 & 33 & 2.9 \\
\hline Hand & 9 & 3.2 & 22 & 2.6 & 31 & 2.7 \\
\hline Chest & 4 & 1.4 & 13 & 1.5 & 17 & 1.5 \\
\hline Arms & 4 & 1.4 & 13 & 1.5 & 17 & 1.5 \\
\hline Face & 4 & 1.4 & 9 & 1.1 & 13 & 1.1 \\
\hline Abdomen & 1 & 0.4 & 7 & 0.8 & 8 & 0.7 \\
\hline Pelvis & 1 & 0.4 & 5 & 0.6 & 6 & 0.5 \\
\hline Calf & 1 & 0.4 & 2 & 0.2 & 3 & 0.3 \\
\hline Head & 1 & 0.4 & 1 & 0.1 & 2 & 0.2 \\
\hline Joint, unspecifi & 1 & 0.4 & 0 & 0 & 1 & 0.1 \\
\hline Stomach & 0 & 0 & 1 & 0.1 & 1 & 0.1 \\
\hline Total & 285 & & 851 & & 1136 & \\
\hline
\end{tabular}

* Percentages do not add up to $100 \%$ because categories are not mutually exclusive.

pain at many more sites [19, 38]. There is strong evidence that differences between the sexes in relation to pain and its relief arise from an interaction of genetic, physiological, neuronal, hormonal and psycho-social factors that modulate pain differently [39]. Furthermore, pain has a significant association with increased age, as other studies have also reported [12, 40]. These studies, along with ours, demonstrate increases in the prevalence of chronic pain to the ages of about 40 to 50 and then either a continuation of increasing prevalence or a plateauing of the prevalence in older age groups. Only $4 \%$ of those in our sample who were less than 40 years of age used GPs for pain management. It is possible that young people self-medicate more frequently. However, pain management in young people is important, because acute pain or exposure to intense pain and stress can be risk factors that contribute to transitions from acute to chronic pain [41]. Our results show that only about $20 \%$ of our sample had incomes that were less than or equal to $€ 36,000$ a year. Although low incomes are described as being risk factors for chronic pain $[42,43]$, we cannot discuss this result because the National Health System in Italy guarantees and safeguards minority patients and those living in poverty and reduces disparities in health. Moreover, about $50 \%$ of the patients in our study had pain that had lasted for up to or more than 48 months and about $25 \%$ of the sample have multisite localizations. These pain characteristics may have negative impacts on the quality of life of the patients [4] and may also lead to important negative socioeconomic and pharmacoeconomic impacts. The main social costs associated with pain are related to loss of productivity, use of health care [44], absenteeism, presenteeism [45] and comorbidity such as depressive symptoms. Our data demonstrate that musculoskeletal pain is more common than mixed and neuropathic pain, as described by two other Italian studies [19, 26]. The different settings could explain this high rate because patients referring to GPs probably have less complex pain than those who seek pain clinics. The most common sites for pain were osteoarthritis, unspecified or localized pain, sciatica and low back pain, and these results are similar to those found by other studies [46]. The reason for the very low number of patients with visceral pain may be that, in Italy, these patients are usually referred to specialized doctors or pain clinics rather than to GPs. In our study, neuropathic pain was associated with patients who were over 70 years of age, those who had one or more sites of pain and those who used adjuvants, such as antidepressants and anticonvulsants, up to six times more than patients affected by musculoskeletal pain. However, our data shows that patients who were under 70 years of age were less likely to suffer from neuropathic pain. These results are described in other studies conducted on PMCs [19]. Furthermore, in accordance with other studies, ours showed that NSAIDs which means that the intensity of the pain is low-mild. Moreover, NSAIDs were used more 
T A B L E 3. Classification and clinical diagnoses of chronic pain according to ICD-9.

\begin{tabular}{|c|c|c|c|c|c|c|}
\hline \multirow[t]{2}{*}{ Classification and Clinical Diagnosis of Chronic Pain* } & \multicolumn{2}{|c|}{ Male $(\mathbf{N}=\mathbf{3 6 0})$} & \multicolumn{2}{|c|}{ Female $(N=1,040)$} & \multicolumn{2}{|c|}{ Total $(\mathrm{N}=1,400)$} \\
\hline & $\mathrm{n}$ & $\%$ & $\mathrm{n}$ & $\%$ & $\mathrm{n}$ & $\%$ \\
\hline \multicolumn{7}{|l|}{ Chronic Musculoskeletal Pain (MSK) } \\
\hline Osteoarthrosis, unspecified generalized or localized & 86 & 23.9 & 262 & 25.2 & 348 & 24.9 \\
\hline Sciatica/low back pain & 63 & 17.5 & 153 & 14.7 & 216 & 15.4 \\
\hline Displacement of intervertebral disc, site unspecified & 50 & 13.9 & 118 & 11.3 & 168 & 12.0 \\
\hline Spondylosis of unspecified site & 23 & 6.4 & 88 & 8.5 & 111 & 7.9 \\
\hline Pain in joint, leg & 23 & 6.4 & 82 & 7.9 & 105 & 7.5 \\
\hline Arthralgia, unspecified & 16 & 4.4 & 73 & 7.0 & 89 & 6.4 \\
\hline Arthritis, unspecified generalized or localized & 15 & 4.2 & 67 & 6.4 & 82 & 5.9 \\
\hline Cervicalgia & 20 & 5.6 & 39 & 3.8 & 59 & 4.2 \\
\hline Fracture lower limb & 6 & 1.7 & 22 & 2.1 & 28 & 2.0 \\
\hline Joint pain, arms & 7 & 1.9 & 15 & 1.4 & 22 & 1.6 \\
\hline Pain in joint, shoulder region & 10 & 2.8 & 10 & 1.0 & 20 & 1.4 \\
\hline Injuries spine, unspecified site & 1 & 0.3 & 15 & 1.4 & 16 & 1.1 \\
\hline Chest pain & 5 & 1.4 & 9 & 0.9 & 14 & 1.0 \\
\hline Fracture upper limb & 4 & 1.1 & 9 & 0.9 & 13 & 0.9 \\
\hline Rheumatoid arthritis & 3 & 0.8 & 8 & 0.8 & 11 & 0.8 \\
\hline Muscle disorders & 3 & 0.8 & 7 & 0.7 & 10 & 0.7 \\
\hline Spinal stenosis, unspecified region & 1 & 0.3 & 4 & 0.4 & 5 & 0,4 \\
\hline Head trauma & 1 & 0.3 & 1 & 0.1 & 2 & 0.1 \\
\hline \multicolumn{7}{|l|}{ Chronic Neuropathic Pain (NP) } \\
\hline Herpes zoster, dermatitis of eyelid or unspecified & 4 & 1.1 & 16 & 1.5 & 20 & 1.4 \\
\hline Polyneuropathy of various etiology & 9 & 2.5 & 7 & 0.7 & 16 & 1.1 \\
\hline Trigeminal neuralgia and other sites & 6 & 1.7 & 9 & 0.9 & 15 & 1.1 \\
\hline Idiopathic peripheral neuropathy & 4 & 1.1 & 7 & 0.7 & 11 & 0.8 \\
\hline Myalgia and myositis, unspecified (fibromyalgia) & 0 & 0 & 5 & 0.5 & 5 & 0.4 \\
\hline \multicolumn{7}{|l|}{ Chronic visceral pain and Other origin } \\
\hline Colic, epigastricpain, dysmenorrhea & 0 & 0 & 8 & 0.8 & 8 & 0.6 \\
\hline \multicolumn{7}{|l|}{ Undefined Chronic Pain } \\
\hline Les, scleroderma, Sjogren syndrome* & 0 & 0 & 6 & 0.6 & 6 & 0.4 \\
\hline
\end{tabular}

ICD-9: International Classification of Diseases, Ninth Revision; NOS: not otherwise specified.

* Percentages do not add up to 100\% because categories are not mutually exclusive.

frequently than opioids, and confirmed the very limited use of adjuvants and acetaminophen [4, 26, 47]. Although the Italian Medicines Agency (AIFA) reports an increase in the use of opioids for the treatment of pain over the last seven years, GPs prefer to prescribe NSAIDs than opioids. The draft guideline recommends that some antidepressants can be considered for people with chronic primary pain. However, they say that benzodiazepines, acetaminophen, NSAIDs and opioids should not be offered because there is little or no evidence that they make any difference to people's quality of life, and there is evidence that they can cause harm, including possible addiction [48]. For their maximum effective or tolerated doses, assessments need to be made of the levels of analgesia produced, and the drugs that did not produce the desired therapeutic effects should be withdrawn. As patients' requirements for analgesia will change over time, periodic and ongoing drug reviews are needed to ensure that the drugs continue to be appropriate, the analgesia is achieving the best possible clinical outcomes and the patients are not experiencing side effects.

\subsection{Limitations}

Although this study offers data about the management of chronic pain in primary care in Italy, it has several limitations. First, a considerable amount of socio-demographic data and intensity of pain are often missing in the databases of the GPs and secondly, these results represent only part of one region in Italy. Also, primary care does not provide an interdisciplinary approach through multidimensional assessments of the patients. Finally, we used a small sample because we included 
TA B L E 4. Univariate and multivariate logistic regression model results.

\begin{tabular}{|c|c|c|c|c|c|c|}
\hline \multirow[t]{2}{*}{ Variables } & \multicolumn{3}{|c|}{ Univariate } & \multicolumn{3}{|c|}{ Multivariate $^{a)}$} \\
\hline & OR & $95 \% \mathrm{CI}$ & $P$-value & OR & $95 \% \mathrm{CI}$ & $P$-value \\
\hline \multicolumn{7}{|l|}{ Sex } \\
\hline Male & 1 & & & & & \\
\hline Female & 0.78 & $0.57-1.07$ & 0.118 & & & \\
\hline \multicolumn{7}{|c|}{ Age (years) } \\
\hline$<70$ & 1 & & & 1 & & \\
\hline$\geq 70$ & 0.66 & $0.50-0.88$ & 0.004 & 0.62 & $0.45-0.85$ & 0.003 \\
\hline \multicolumn{7}{|c|}{$N^{\circ}$ of sites with pain } \\
\hline 0 & 1 & & & & & \\
\hline 1 & 2.62 & $1.55-4.43$ & $<0.001$ & 2.59 & $1.49-4.51$ & 0.001 \\
\hline 2 & 5.58 & $3.20-9.75$ & $<0.001$ & 6.14 & $3.40-11.11$ & $<0.001$ \\
\hline $3+$ & 6.06 & $2.60-14.12$ & $<0.001$ & 5.68 & $2.30-14.06$ & $<0.001$ \\
\hline
\end{tabular}

Duration of pain (months)

\begin{tabular}{lccc}
$<48$ & 1 & & \\
$\geq 48$ & 1.10 & $0.83-1.46$ & 0.491 \\
\hline Fans +/- Opioid use & & & \\
\hline No & 1 & & \\
Yes & 0.27 & $0.16-0.47$ & $<0.001$
\end{tabular}

Antidepressive +/- Anticonvulsants use

\begin{tabular}{lccccccc} 
No & 1 & \multicolumn{5}{c}{1} & \\
Yes & 6.25 & $4.42-8.84$ & $<0.001$ & 6.82 & $4.74-9.81$ & $<0.001$ \\
\hline
\end{tabular}

${ }^{\text {a) }}$ Forward selection; $O R=$ odds ratio; $95 \% C I=95 \%$ Confidence Interval.

only patients who had been affected by chronic pain for six months or more, so we could understand the sample in this study.

\section{Conclusions}

Chronic pain requires personalized management according to a bio-psycho-social model. It is useful for GPs and their patients to discuss and agree on treatment goals before initiating treatment, to have objective standards against which to assess treatment success or failure. An overall reduction of pain intensity is the first outcome, but patients need to improve the quality of their lives, which GPs alone cannot guarantee. The measurement of pain intensity is not often documented in primary care, and the high number of patients taking anti-inflammatories, which probably means that the intensity of the pain is low-mild. It is important to consolidate one interdisciplinary approach through other disciplines such as Nursing and Psychology to maximize the results in terms of quality of life, adherence and costs [49, 50]. Moreover, an optimal transitional process from GPs to PMCs should be tested to prevent the needless suffering of those with chronic pain.

\section{AUTHOR CONTRIBUTIONS}

AC, AR, RL, GT, MDM, GV and GN designed the research study. AC, AR, RF, AP, LI, and DD performed the research. DG, IT, GC and RL analyzed the data. RL, PM, LI, GT and AR wrote the manuscript. All authors contributed to editorial changes in the manuscript. All authors read and approved the final manuscript.

\section{ACKNOWLEDGEMENTS}

The authors are particularly grateful to the GPs that accepted to make their data available for the study. Without their support, this study would not have been possible.

\section{FUNDING}

None was received.

\section{CONFLICT OF INTEREST}

The authors declare no competing interests.

\section{REFERENCES}

[1] Institute of Medicine. Committee on Advancing Pain Research Care and Education. The National Academies collection: reports funded by 
national institutes of health. relieving pain in America: a blueprint for transforming prevention, care, education, and research. National Academies Press. 2011.

[2] Gerbershagen HU, Lindena G, Korb J, Kramer S. Health-related quality of life in patients with chronic pain. Schmerz. 2002; 16: 271-284.

[3] Dysvik E, Lindstrøm TC, Eikeland OJ, Natvig GK. Health-related quality of life and pain beliefs among people suffering from chronic pain. Pain Management Nursing. 2004; 5: 66-74.

[4] Paterniani A, Sperati F, Esposito G, Cognetti G, Pulimeno AML, Rocco $\mathrm{G}$, et al. Quality of life and disability of chronic non-cancer pain in adults patients attending pain clinics: A prospective, multicenter, observational study. Applied Nursing Research. 2020; 14: 151332.

[5] Von Korff M, Lin EH, Fenton JJ, Saunders K. Frequency and priority of pain patients' health care use. Clinical Journal of Pain. 2007; 23: 400-408.

[6] Leadley RM, Armstrong N, Lee YC, Allen A, Kleijnen J. Chronic diseases in the European Union: the prevalence and health cost implications of chronic pain. Journal of Pain and Palliative Care Pharmacotherapy. 2012; 26: 310-325.

[7] Lynch ME, Schopflocher D, Taenzer P, Sinclair C. Research funding for pain in Canada. Pain Res Manag. 2009; 14: 113-115.

[8] Angeles RN, Guenter D, McCarthy L, Bauer M, Wolfson M, Chacon M, et al. Group interprofessional chronic pain management in the primary care setting: a pilot study of feasibility and effectiveness in a family health team in Ontario. Pain Research and Management. 2013; 18: 237-242.

[9] Treede RD, Rief W, Barke A, Aziz Q, Bennett MI, Benoliel R, et al. Chronic painas a symptom or a disease: the IASP Classification of chronic pain for the International Classification of Diseases (ICD-11). Pain. 2019; 160: 19-27.

[10] Andrew R, Derry S, Taylor RS, Straube S, Phillips CJ. The costs and consequences of adequately managed chronic non-cancer pain and chronic neuropathic pain. Pain Practice. 2014; 14: 79-94.

[11] Del Giorno R, Frumento P, Varrassi G, Paladini A, Coaccioli S. Assessment of chronic pain and access to pain therapy: a cross-sectional population-based study. Journal of Pain Research. 2017; 10: 2577-2584.

[12] Azevedo LF, Costa-Pereira A, Mendonça L, Dias CC, Castro-Lopes JM. Epidemiology of chronic pain: a population-based nationwide study on its prevalence, characteristics and associated disability in Portugal. Journal of Pain. 2012; 13: 773-783.

[13] Kurita GP, Sjøgren P, Juel K, Højsted J, Ekholm O. The burden of chronic pain: a cross-sectional survey focussing on diseases, immigration, and opioid use. Pain. 2012; 153: 2332-2338.

[14] Flüß E, Bond CM, Jones GT, Macfarlane GJ. The re-evaluation of the measurement of pain in population-based epidemiological studies: The SHAMA study. Brazilian Journal of Pain. 2015; 9: 134-41.

[15] Patel KV, Guralnik JM, Dansie EJ, Turk DC. Prevalence and impact of pain among older adults in the united states: findings from the 2011 national health and aging trends study. Pain. 2013; 154: 2649-57.

[16] Raftery MN, Sarma K, Murphy AW, De la Harpe D, Normand C, McGuire BE. Chronic pain in the Republic of Ireland-community prevalence, psychosocial profile and predictors of pain-related disability: results from the prevalence, impact and cost of chronic pain (PRIME) study, part 1. Pain. 2011; 152: 1096-103.

[17] Molton IR, Terrill AL. Overview of persistent pain in older adults. American Psychologist. 2014; 69: 197-207.

[18] Mogil JS. Sex differences in pain and pain inhibition: multiple explanations of a controversial phenomenon. Nature Reviews Neuroscience. 2012; 13: 859-866.

[19] Latina R, De Marinis MG, Giordano F, Osborn JF, Giannarelli D, Di Biagio E, et al. Epidemiology of chronic pain in the Latium region, Italy: A cross-sectional study on the clinical characteristics of patients attending pain clinics. Pain Management Nursing. 2019; 20: 373-381.

[20] Langley PC, Ruiz-Iban MA, Molina JT, De Andres J, Castellón JR. The prevalence, correlates and treatment of pain in Spain. Journal of Medical Economics. 2011; 14: 367-380.

[21] Andersson HIEG, Leden I, Schersten B. Impact of chronic pain on health care seeking, self care, and medication. Results from a population-based Swedish study. Journal of Epidemiology and Community Health. 1999; 53: 503-509.

[22] Mäntyselkä PT, Turunen JH, Ahonen RS, Kumpusalo EA. Chronic pain and poor self-rated health. Journal of the American Medical Association.
2003; 290: 2435-2442.

[23] Smith BH, Hardman JD, Stein A, Colvin L. Managing chronic pain in the non-specialist setting: a new SIGN guideline. British Journal of General Practice. 2014; 64: e462-e4.

[24] Dobscha SK, Corson K, Perrin NA, Hanson GC, Leibowitz RQ, Doak $\mathrm{MN}$, et al. Collaborative care for chronic pain in primary care: a cluster randomized trial. Journal of the American Medical Association. 2009; 301: 1242-1252.

[25] D'Angelo D, Chiara M, Vellone E, Alvaro R, Casale G, Stefania L, et al. Transitions between care settings after enrolment in a palliative care service in Italy: a retrospective analysis. International Journal of Palliative Nursing. 2013; 19: 110-115.

[26] Koleva D, Krulichova I, Bertolini G, Caimi V, Garattini L. Pain in primary care: an Italian survey. European Journal of Public Health. 2005; 15: 475-

[27] Leuter C, Piroli A, Paladini A, Tudini M, Varrassi G. Care strategies and therapeutic pathways for chronic pain patients in Abruzzo Region, Italy. Annali di Igiene. 2017; 29: 63-72.

[28] Guthrie B, Payne K, Alderson P, McMurdo ME, Mercer SW. Adapting clinical guidelines to take account of multimorbidity. British Medical Journal. 2012; 345: e6341.

[29] Pannek J, Pannek-Rademacher S, Wöllner J. Use of complementary and alternative medicine in persons with spinal cord injury in Switzerland: a survey study. Spinal Cord. 2015; 53: 569-72.

[30] Smith BH, Hopton JL, Chambers WA. Chronic pain in primary care. Family Practice. 1999; 16: 475-482.

[31] Dworkin RH, Turk DC, Wyrwich KW, Beaton D, Cleeland CS, Farrar JT, et al. Interpreting the clinical importance of treatment outcomes in chronic pain clinical trials: IMMPACT recommendations. Journal of Pain. 2008; 9: $105-121$.

[32] Dubois MY, Follett KA. Pain medicine: the case for an independent medical specialty and training programs. Academic Medicine. 2014; 89: 863-868.

[33] Damico V, Murano L, Cazzaniga F, Dal Molin A. Pain prevalence, severity, assessment and management in hospitalized adult patients: a result of a multicenter cross-sectional study. Annali dell' Istituto Superiore di Sanita. 2018; 54: 194-200.

[34] Corsi N, Roberto A, Cortesi L, Nobili A, Mannucci PM, Corli O, et al. Prevalence, characteristics and treatment of chronic pain in elderly patients hospitalized in internal medicine wards. European Journal of Internal Medicine. 2018; 55: 35-39.

[35] Latina R, De Marinis MG, Baglìo G, Cattaruzza MS, Notaro P, Guzzetti $\mathrm{V}$, et al. Features and organization of pain centers in the Lazio Region, Italy, in 2011. Annali di Igiene. 2014; 26: 367-379.

[36] von Elm E, Altman DG, Egger M, Pocock SJ, Gøtzsche PC, Vandenbroucke JP, et al. The strengthening the reporting of observational studies in epidemiology (STROBE) statement: guidelines for reporting observational studies. Annals of Internal Medicine. 2007; 147: 573-577.

[37] International Association for the Study of Pain (IASP). Classification of chronic pain. Descriptions of chronic pain syndromes and definitions of pain terms. IASP Press. 1994

[38] Cabrera-León A, Cantero-Braojos MÁ, Garcia-Fernandez L, Guerra de Hoyos JA. Living with disabling chronic pain: results from a face-to-face cross-sectional population-based study. BMJ Open. 2018; 8: e020913.

[39] Pieretti S, Di Giannuario A, Di Giovannandrea R, et al. Gender differences in pain and its relief. Annali dell'Istituto Superiore di Sanita. 2016; 52: 184-189.

[40] Mansfield KE, Sim J, Jordan JL, Marzoli F, Piccaro G, Minosi P, et al. A systematic review and meta-analysis of the prevalence of chronic widespread pain in the general population. Pain. 2016; 157: 55-64.

[41] Kyranou M, Puntillo K. The transition from acute to chronic pain: might intensive care unit patients be at risk? Annals of Intensive Care. 2012; 2: 36.

[42] Newman AK, Kapoor S, Thorn BE. Health care utilization for chronic pain in low-income settings. Pain Medicine. 2018; 19: 2387-2397.

[43] Day MA, Thorn BE. The relationship of demographic and psychosocial variables to pain-related outcomes in a rural chronic pain population. Pain. 2010; 151: 467-74.

[44] Grimby-Ekman A, Gerdle B, Björk J, Larsson B. Comorbidities, intensity, frequency and duration of pain, daily functioning and health 
care seeking in local, regional, and widespread pain-a descriptive population-based survey (SwePain). BMC Musculoskeletal Disorders. 2015; 16: 165.

[45] Hemp P. Presenteeism: at work-but out of it. Harvard Business Review. 2004; 82: 49-58

[46] Quintana R, Silvestre AM, Goñi M, García V, Mathern N, Jorfen M, et al. Prevalence of musculoskeletal disorders and rheumatic diseases in the indigenous Qom population of Rosario, Argentina. Clinical Rheumatology. 2016; 35: 5-14.

[47] Fredheim OM, Skurtveit S, Breivik H, Borchgrevink PC. et al. Increasing use of opioids from 2004 to 2007-pharmacoepidemiological data from a complete national prescription database in Norway. European Journal of Pain. 2010; 14: 289-294.

[48] National Institute for Health and Care Excellence (NICE). Neuropathic pain in adults: pharmacological management in non-specialist settings.
Clinical guideline [CG173]. 2013. Available at: https://www.nice. org.uk/guidance/cg173/chapter/1-Recommendations.

[49] O'Connor AB. Neuropathic pain: quality-of-life impact, costs and cost effectiveness of therapy. Pharmacoeconomics. 2009; 27: 95-112.

[50] Iacorossi L, Gambalunga F, Fabi A, Giannarelli D, Facchinetti G, Piredda $\mathrm{M}$, et al. Adherence to hormone therapy in women with breast cancer: a quantitative study. Professioni Infermieristiche. 2016; 69: 113-121.

How to cite this article: Camilloni Arianna, Nati Giulio, Maggiolini Paolo, et al. Chronic non-cancer pain in primary care: an Italian cross-sectional study. Signa Vitae. 2021;17(2):54-62. doi: $10.22514 /$ sv.2020.16.0111. 